\title{
Re: Low-intensity Shockwave Therapy for Erectile Dysfunction in Kidney Transplants Recipients. A Prospective, Randomized, Double Blinded, Sham-Controlled Study with Evaluation By Penile Doppler Ultrasonography
}

\author{
Yamaçake KGR1, Carneiro F2, Cury J1, Lourenço R1, Françolin PC2, Piovesan AC1, Srougi M1, Nahas WC1, Antonopoulos IM1 \\ 1São Paulo University Faculty of Medicine, Department of Urology, São Paulo, Brazil \\ 2São Paulo University Faculty of Medicine, Department of Radiology, São Paulo, Brazil
}

Int J Impot Res. 2019;31(3):195-203. doi: 10.1038/s41443-018-0062-2

\section{EDITORIAL COMMENT}

Erectile dysfunction (ED) remains a very common problem in patients with end-stage renal disease even among kidney transplant recipients. Nonsurgical treatment alternatives for ED consist of oral phosphodiesterase type 5 inhibitors and intracavernosal injections of vasodilating agents. In this double-blind, single-center, prospective, randomized, and sham-controlled trial, the authors evaluated the efficacy of low-intensity extracorporeal shockwave therapy (Li-ESWT) for the first time for the treatment of ED in 20 kidney transplanted men. The patients were followed for 12 months with International Index of Erectile Function Questionnaire (IIEF) score, Erection Hardness score (EHS) and penile Doppler. The mean IIEF and EHS scores were better on every follow-up in the Li-ESWT group, however, no difference was observed in penile Doppler findings. In this setting, Li-ESWT appears to be a treatment alternative for the treatment of ED in kidney transplant recipients. Nevertheless, the mechanism of action is suggesting neoangiogenesis; this effect has not been confirmed by penile Doppler in this study.

Yarkın Kamil Yakupoğlu, MD 